\title{
Invasive tests for Helicobacter pylori in children
}

\author{
Hien Q Huynh MBBS FRACP
}

\begin{abstract}
HQ Huynh. Invasive tests for Helicobacter pylori in children. Can J Gastroenterol 2005;19(7):429-432.
\end{abstract}

\section{Tests effractifs pour Helicobacter pylori chez les enfants}

L'une des premières indications de l'endoscopie des voies digestives hautes chez les enfants est la présence de symptômes persistants et sévères. L'endoscopie des voies digestives hautes permet au médecin de confirmer ou d'écarter un diagnostic concernant cette portion de l'appareil digestif. De plus, l'endoscopie, avec biopsie de la muqueuse, constitue la norme diagnostique pour le dépistage de l'infection à Helicobacter pylori et de ses complications chez les enfants. Les biopsies gastriques peuvent être utilisées pour le test rapide à l'uréase, et l'examen histologique et la culture bactérienne permettent de déterminer la sensibilité aux antibiotiques. L'ADN extrait des spécimens de biopsies peut également être soumis à un génotypage grâce aux méthodes moléculaires pour confirmer la présence d'une infection à $H$ pylori, une mutation entraînant sa résistance aux antibiotiques ou ses facteurs de virulence.

Key Words: Children; Endoscopy; H pylori; Histology; Invasive; Molecular diagnostics

Currently, upper gastrointestinal (GI) endoscopy with - $m u c o s a l$ biopsies remains the gold standard for the diagnosis of Helicobacter pylori infection in children. The added advantage of endoscopy includes the detection of upper gastrointestinal pathologies including complications of $H$ pylori infection such as nodular gastritis, peptic ulcer disease and gastric cancer, and mucosa-associated lymphoid tissue lymphoma. The biopsies obtained can be used for bacterial culture, determining antibiotic sensitivity and bacterial genotyping. The need for anesthesia in children, the high cost and small risks of perforation and aspiration pneumonia are some of the disadvantages of endoscopy.

One of the primary indications for upper GI endoscopy in children is the presence of persistent and severe upper abdominal symptoms, to detect upper GI tract pathologies and not simply the presence of $\mathrm{H}$ pylori. It is not clinically possible to differentiate between complications in $\mathrm{H}$ pylori-infected children and other upper GI pathologies or functional dyspepsia. In a retrospective cohort study (1), 52 of 2550 children who had undergone upper GI endoscopy were found to have peptic ulcers (1). Apart from vomiting (found more frequently in those without pathology), no statistical difference was noted in symptomatology between those with and without peptic ulcers. In the subgroup with peptic ulcer disease, symptoms did not differ between $H$ pylori-infected and -noninfected individuals $(1,2)$. Nevertheless, children with a family history of peptic ulcer disease are more likely to have H pylori infection (3).

The gastritis secondary to $H$ pylori infection is not always evident endoscopically, but can be seen in histological examination of gastric biopsies. The most common endoscopic finding in children with $\mathrm{H}$ pylori infection is nodular gastritis, often seen more in the antrum than the body of the stomach (4). Nodular gastritis can be identified when the gastric mucosa has an irregular 'cobblestone' appearance, highlighted with blood from a bleeding biopsy site. There is a significant association between nodular gastritis and $H$ pylori infection. Nodular gastritis was found in $45 \%$ of $\mathrm{H}$ pylori-infected and $1.5 \%$ of -noninfected children (4), and its prevalence increased with age (5). The authors of these studies $(4,5)$ concluded that nodular hyperplasia or gastritis is highly specific $(98.5 \%)$ and, therefore, has a high positive predictive value for $\mathrm{H}$ pylori infection, but low sensitivity (44\%). The absence of nodular hyperplasia does not preclude the presence of infection. In addition, there is a positive correlation among nodular hyperplasia, severity of gastritis and bacteria density (4).

\section{Biopsy site}

\section{TESTS FOR DETECTING H PYLORI}

At least two biopsies from one or more regions of the stomach (body, antrum and transitional zone, ie, cardia and incisura) are required for diagnosis (6). In patients who have not received treatment, an antral biopsy has a much higher yield than biopsies obtained from the body in $\mathrm{H}$ pylori detection (94\% versus $73 \%$, respectively). The region that has the highest detection rate is the midantrum region of the lesser curvature (6). Often biopsies from the transitional zone and body are also required to improve the yield in patients who have been treated with acid suppression therapy or antibiotics $(7,8)$. For 
those with complications of $\mathrm{H}$ pylori infection, such as peptic ulcer disease, it is recommended to have biopsies from multiple regions of the stomach.

\section{Histological staining of biopsy section}

Histological detection of $H$ pylori remains an affordable and reliable method in comparison with other assays (9). In the majority of cases, $\mathrm{H}$ pylori can be seen with hematoxylin and eosin staining; however, this method has a lower sensitivity and most laboratories use alternative staining methods for improved detection. Polyclonal anti-H pylori antibody staining is regarded as a reliable assay; however, this method is expensive and time consuming (10). In comparison, the Giemsa stain, although less reliable, is widely available, affordable and can be readily prepared. The optimal staining method is often best determined by the expertise available locally.

\section{Rapid urease tests}

Numerous urease tests are commercially available. Urease is a metalloenzyme produced in abundance by $H$ pylori (11). Urease converts urea to ammonia, thereby increasing the $\mathrm{pH}$ in the bacterium's microenvironment. Urease tests are highly specific and sensitive for indirectly detecting $H$ pylori infection in adults (11). In children, however, its sensitivity is much lower and false-negative results are produced. The lower sensitivity could be secondary to reduced urease activity in $H$ pylori strains isolated from children and lower bacterial load (12). The accuracy of urease tests, like histological examination, is also dependent on the number of biopsies taken, sites of biopsy and the use of antibiotics and proton pump inhibitors (13).

\section{H pylori culture}

$H$ pylori is a fastidious organism and is difficult to culture from gastric biopsy. Bacterial culturing is also time consuming and expensive. In one study (14), culture tests had a low sensitivity, with positive results in only $70 \%$ of $H$ pylori-infected children. However, bacterial culture tests allow for antibiotic sensitivity to be determined, which is particularly useful in those who have failed previous eradication therapy. Various antibiotic susceptibility tests are also available, including the epsilometer (E)-test, disc test and agar dilution methods. The Clinical and Laboratory Standards Institute (formerly known as the National Committee for Clinical Laboratory Standards) recommends agar dilution as the method of choice for antibiotic sensitivity testing in $\mathrm{H}$ pylori infection (15). A positive culture test also allows for the opportunity to genotype clinical isolates for specific virulence factors (a method employed in the research setting).

\section{Molecular diagnostics using gastric tissue}

Over the past few years, advances have been made using rapid molecular diagnostics to detect $H$ pylori infection, antibiotic sensitivity, the presence of specific virulence factors and the patient's genotype (as reviewed by Simala-Grant and Taylor [16] and Ruzsovics et al [17]). These molecular diagnostic tests may allow for more cost-effective and individualized treatment, resulting in improved eradication rates, and reduction in antibiotic-resistant strains.

Molecular methods for detecting $\mathrm{H}$ pylori in gastric biopsies The polymerase chain reaction (PCR) is highly sensitive in detecting microbes in human tissue. Using paired primers directed at a region of the urease A gene or glmM (ureC gene) of $H$ pylori $(10,18)$, it was found that although nested PCR performed on gastric biopsy specimens was sensitive, it was not as specific as histopathology and the rapid urease test for detecting $H$ pylori infection.

Recently, three studies (19-21) have used real-time PCR to detect and quantify $H$ pylori infection directly from gastric biopsy specimens. He et al (19), using this technique with a LightCycler apparatus (Roche Diagnostics, USA) and a frozen section, amplified a fragment of the ureC gene, but a low specificity was achieved (a high number of specimens were positive by real-time PCR but negative by culture and histology). Lascols et al (20), however, demonstrated with the same apparatus that targeting the 23S ribosomal (r)RNA gene in frozen section by real-time PCR gave a sensitivity of $97 \%$ and a specificity of $94.6 \%$ (infection was defined as a positive culture, histology or positive PCR, if confirmed by a positive concomitant serology or urea breath test). In addtion, Kobayashi et al (21) used the TagMan apparatus and a paraffin section to target the 16S rRNA gene and had both the highest sensitivity and specificity (100\%) compared with culture tests, histology, the urea breath test and rapid urease test. The detection of $H$ pylori on gastric specimens by real-time PCR is very promising; however, more clinical studies are needed to determine the optimal target gene and confirm its reliability.

\section{Molecular methods to detect $\mathrm{H}$ pylori with antibiotic resistance genotypes}

PCR, when performed on cultured clinical isolates or directly on gastric biopsies obtained from infected individuals, has been used to determine the antibiotic sensitivity of $H$ pylori strains, particularly with respect to clarithromycin. The predominant cause of clarithromycin resistance is a point mutations in the peptidyl transferase of the 23S rRNA gene (22). Using LightCycler real-time PCR to detect these point mutations, Chisholm et al (22) demonstrated a strong correlation between wild type and clarithromycin sensitivity in 47 of 48 strains of $H$ pylori. Four strains had clarithromycin resistance mutations, but only two demonstrated resistance when assessed by disk diffusion. There were four PCR-negative specimens, and three were sensitive to clarithromycin; the reliability of this test was unclear. However, in a recent study, Lascols et al (20) showed a very high concordance rate of 98.3\% (58 of 59) comparing clarithromycin susceptibility testing with E-test and LightCycler real-time PCR. The prevalence of clarithromycin resistance was $18.5 \%$ in that study. Thus, the use of real-time PCR in the detection of H pylori with clarithromycin resistance genotypes is likely to be a valuable tool.

Fluorescent in situ hybridization using labelled oligonucleotides can be used to detect $H$ pylori by probing for $H$ pylorispecific 16S rRNA and point mutations in the 23S rRNA of clarithromycin-resistant strains (23). This technique can be used in both frozen as well as formalin-fixed and paraffinembedded gastric biopsy sections, and is reliable in detecting clarithromycin-resistant H pylori (24-26).

Mutations in the $r d x \mathrm{~A}$ gene encoding for a nitroreductase (which converts metronidazole from a harmless prodrug to a bactericidal agent) may result in $H$ pylori resistance to metronidazole (27). In other reductase genes, such as $f d x B$ (encoding for ferrodoxin-like protein) and frxA (encoding for flavin 
nitroreductase), inactivating mutations enhance metronidazole resistance (28). It is likely that there are other reductases that are involved in $H$ pylori resistance to metronidazole (29-31). These studies (29-31) suggest that there are multiple $H$ pylori proteins involved in reducing metronidazole, and the contribution of each of these proteins to metronidazole resistance is likely variable in different strains, making it more difficult to develop a reliable molecular method determining metronidazole susceptibility.

In a recent study (32), fluorescence resonance energy transferbased real-time PCR performed on bacterial DNA isolated from pure culture was used to detect point mutations in the gyrA gene, which confers resistance to ciprofloxacin in $H$ pylori. This assay appears reliable when compared with the E-test in $100 \mathrm{H}$ pylori isolates (32). However, the sensitivity and specificity will need to be evaluated in the clinical setting, preferably using biopsy specimens.

The presence of amoxil resistance in $H$ pylori is rarely reported. A single amino acid substitution in HP0597, a penicillin-binding protein $1 \mathrm{~A}$ homologue of Escherichia coli, was demonstrated in an amoxil-resistant strain of $H$ pylori (33). Similar to metronidazole resistance, there likely are other proteins involved in conferring amoxil resistance. The mechanism of amoxil resistance is still not well understood. Currently, a molecular diagnostic test is not available for the detection of amoxil resistance.

PCR-based assays have been developed to detect a restriction length polymorphism associated with a triple base pair

\section{REFERENCES}

1. Roma E, Kafritsa Y, Panayiotou J, Liakou R, Constantopoulos A. Is peptic ulcer a common cause of upper gastrointestinal symptoms? Eur J Pediatr 2001;160:497-500.

2. Elitsur Y, Lawrence Z. Non-Helicobacter pylori related duodenal ulcer disease in children. Helicobacter 2001;6:239-43.

3. Nijevitch AA, Shcherbakov PL. Helicobacter pylori and gastrointestinal symptoms in school children in Russia. J Gastroenterol Hepatol 2004;19:490-6.

4. Bahu Mda G, da Silveira TR, Maguilnick I, Ulbrich-Kulczynski J. Endoscopic nodular gastritis: An endoscopic indicator of high-grade bacterial colonization and severe gastritis in children with Helicobacter pylori. J Pediatr Gastroenterol Nutr 2003;36:217-22

5. Rafeey M, Jafari Rouhi AH, Gassemi BA, Rouhi AJ. Relationship between endoscopic nodular gastritis and Helicobacter pylori infection in children. Indian J Gastroenterol 2004;23:138-9.

6. Elitsur Y, Lawrence Z, Triest WE. Distribution of Helicobacter pylori organisms in the stomachs of children with $H$ pylori infection. Hum Pathol 2002;33:1133-5.

7. Van Zanten SJ, Dixon MF, Lee A. The gastric transitional zones: Neglected links between gastroduodenal pathology and helicobacter ecology. Gastroenterology 1999;116:1217-29.

8. Logan RP, Walker MM, Misiewicz JJ, Gummett PA, Karim QN, Baron JH. Changes in the intragastric distribution of Helicobacter pylori during treatment with omeprazole. Gut 1995;36:12-6.

9. Brooks HJ, Ahmed D, McConnell MA, Barbezat GO. Diagnosis of Helicobacter pylori infection by polymerase chain reaction: Is it worth it? Diagn Microbiol Infect Dis 2004;50:1-5.

10. Rotimi O, Cairns A, Gray S, Moayyedi P, Dixon MF. Histological identification of Helicobacter pylori: Comparison of staining methods. J Clin Pathol 2000;53:756-9.

11. Ho CY, Chen TS, Chang FY, Lee SD. Rapid urease test from nonulcer part of stomach is superior to histology from ulcer in detection of Helicobacter pylori infection in patients with gastric ulcer. Hepatogastroenterology 2004;51:1877-80.

12. Chu C, Yu YJ, Kong MS, Ou JT. Rate of Helicobacter pylori infection in children and clonality of Taiwan strains. Microbiol Immunol 2003;47:813-21.

13. el-Zimaity HM, al-Assi MT, Genta RM, Graham DY. substitution (adenine-guanine-adenine [926-928]/thyminethymine-cytosine) in the $16 \mathrm{~S}$ rRNA gene (34). This substitution is associated with tetracycline resistance (34); however, the accuracy of this mutation in determining tetracycline resistance is unknown.

\section{Virulence genotyping}

Numerous PCR methods (real-time PCR, PCR-length polymorphism, PCR-restriction fragment length polymorphism and line prop assay) have been used to determine the presence of $H$ pylori virulence genes such as cagA, cagE, vacA, babA and ice $A$ in fresh and paraffin-embedded tissues, or from DNA isolated from bacterial culture (35). These virulent genotypes have been associated with a more severe disease outcome; however, these results are debatable (36). The relevance of virulent genotyping in clinical practice remains to be determined.

\section{CONCLUSIONS}

One of the primary indications for upper GI endoscopy in children is the presence of persistent and severe upper abdominal symptoms. Upper GI endoscopy with mucosal biopsies remains the gold standard for the detection of $\mathrm{H}$ pylori infection and its mucosal complications in children. Molecular methods can be employed using obtained gastric biopsies to determine the presence of $\mathrm{H}$ pylori infection, antibiotic resistance and $H$ pylori virulence factors. In the future, it is likely that these molecular methods will become more widely used in the clinical setting and allow for individualized treatment.

Confirmation of successful therapy of Helicobacter pylori infection: Number and site of biopsies or a rapid urease test.

Am J Gastroenterol 1995;90:1962-4.

14. Tolia V, Brown W, El-Baba M, Lin CH. Helicobacter pylori culture and antimicrobial susceptibility from pediatric patients in Michigan. Pediatr Infect Dis J 2000;19:1167-71.

15. Duck WM, Sobel J, Pruckler JM, et al. Antimicrobial resistance incidence and risk factors among Helicobacter pylori-infected persons, United States. Emerg Infect Dis 2004;10:1088-94.

16. Simala-Grant JL, Taylor DE. Molecular biology methods for the characterization of Helicobacter pylori infection and their diagnosis. APMIS 2004;112:886-97.

17. Ruzsovics A, Molnar B, Tulassay Z. Review article: Deoxyribonucleic acid-based diagnostic techniques to detect Helicobacter pylori. Aliment Pharmacol Ther 2004;19:1137-46.

18. Vinette KM, Gibney KM, Proujansky R, Fawcett PT. Comparison of PCR and clinical laboratory tests for diagnosing $H$ pylori infection in pediatric patients. BMC Microbiol 2004;4:5

19. He Q, Wang JP, Osato M, Lachman LB. Real-time quantitative PCR for detection of Helicobacter pylori. J Clin Microbiol 2002;40:3720-8

20. Lascols C, Lamarque D, Costa JM, et al. Fast and accurate quantitative detection of Helicobacter pylori and identification of clarithromycin resistance mutations in $H$ pylori isolates from gastric biopsy specimens by real-time PCR. J Clin Microbiol 2003;41:4573-7.

21. Kobayashi D, Eishi Y, Ohkusa T, et al. Gastric mucosal density of Helicobacter pylori estimated by real-time PCR compared with results of urea breath test and histological grading. J Med Microbiol 2002;51:305-11.

22. Chisholm SA, Owen RJ, Teare EL, Saverymuttu S. PCR-based diagnosis of Helicobacter pylori infection and real-time determination of clarithromycin resistance directly from human gastric biopsy samples. J Clin Microbiol 2001;39:1217-20.

23. Trebesius K, Panthel K, Strobel S, et al. Rapid and specific detection of Helicobacter pylori macrolide resistance in gastric tissue by fluorescent in situ hybridisation. Gut 2000;46:608-14.

24. Juttner S, Vieth M, Miehlke S, et al. Reliable detection of macrolide-resistant Helicobacter pylori via fluorescence in situ hybridization in formalin-fixed tissue. Mod Pathol 2004;17:684-9. 
25. Russmann H, Kempf VA, Koletzko S, Heesemann J, Autenrieth IB. Comparison of fluorescent in situ hybridization and conventional culturing for detection of Helicobacter pylori in gastric biopsy specimens. J Clin Microbiol 2001;39:304-8.

26. Russmann H, Feydt-Schmidt A, Adler K, Aust D, Fischer A, Koletzko S. Detection of Helicobacter pylori in paraffin-embedded and in shock-frozen gastric biopsy samples by fluorescent in situ hybridization. J Clin Microbiol 2003;41:813-5.

27. Yang YJ, Wu JJ, Sheu BS, Kao AW, Huang AH. The $r d x A$ gene plays a more major role than frxA gene mutation in high-level metronidazole resistance of Helicobacter pylori in Taiwan. Helicobacter 2004;9:400-7.

28. Bereswill S, Krainick C, Stahler F, Herrmann L, Kist M. Analysis of the $r d x A$ gene in high-level metronidazole-resistant clinical isolates confirms a limited use of $r d x A$ mutations as a marker for prediction of metronidazole resistance in Helicobacter pylori. FEMS Immunol Med Microbiol 2003;36:193-8.

29. Jorgensen MA, Trend MA, Hazell SL, Mendz GL. Potential involvement of several nitroreductases in metronidazole resistance in Helicobacter pylori. Arch Biochem Biophys 2001;392:180-91.

30. Chisholm SA, Owen RJ. Frameshift mutations in frxA occur frequently and do not provide a reliable marker for metronidazole resistance in UK isolates of Helicobacter pylori. J Med Microbiol 2004;53:135-40.

31. Chisholm SA, Owen RJ. Mutations in Helicobacter pylori rdxA gene sequences may not contribute to metronidazole resistance. J Antimicrob Chemother 2003:51:995-9.

32. Glocker E, Kist M. Rapid detection of point mutations in the gyrA gene of Helicobacter pylori conferring resistance to ciprofloxacin by a fluorescence resonance energy transfer-based real-time PCR approach. J Clin Microbiol 2004;42:2241-6.

33. Gerrits MM, Schuijffel D, van Zwet AA, Kuipers EJ, Vandenbroucke Grauls CM, Kusters JG. Alterations in penicillinbinding protein $1 \mathrm{~A}$ confer resistance to beta-lactam antibiotics in Helicobacter pylori. Antimicrob Agents Chemother 2002;46:2229-33.

34. Ribeiro ML, Gerrits MM, Benvengo YH, et al. Detection of high-level tetracycline resistance in clinical isolates of Helicobacter pylori using PCR-RFLP. FEMS Immunol Med Microbiol 2004:40:57-61

35. Boonjakuakul JK, Syvanen M, Suryaprasad A, Bowlus CL, Solnick JV. Transcription profile of Helicobacter pylori in the human stomach reflects its physiology in vivo. J Infect Dis 2004;190:946-56.

36. Salih BA. The role of the putative virulence markers (cagA and vacA) of Helicobacter pylori in peptic ulcer disease. Saudi Med J 2004;25:830-6. 


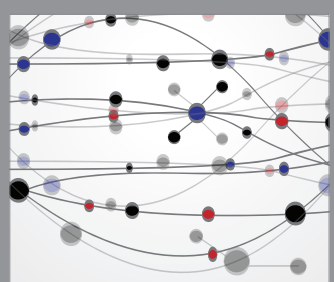

The Scientific World Journal
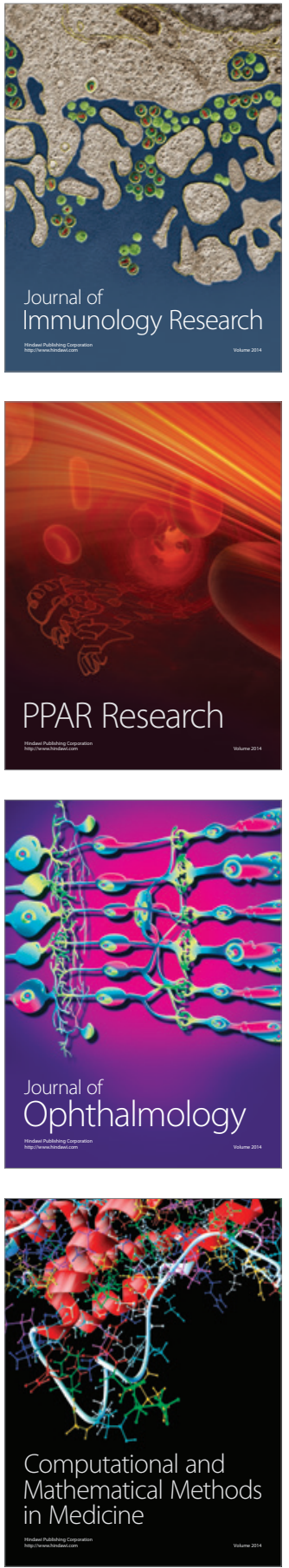

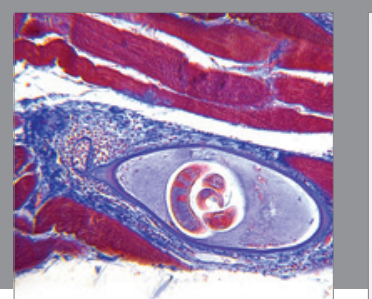

Gastroenterology Research and Practice

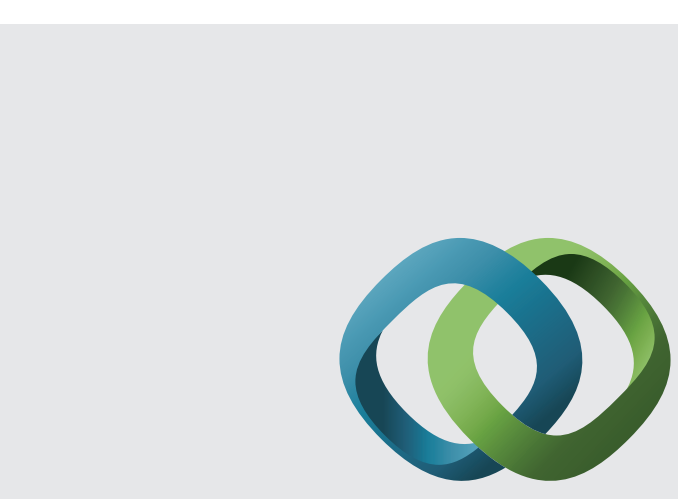

\section{Hindawi}

Submit your manuscripts at

http://www.hindawi.com
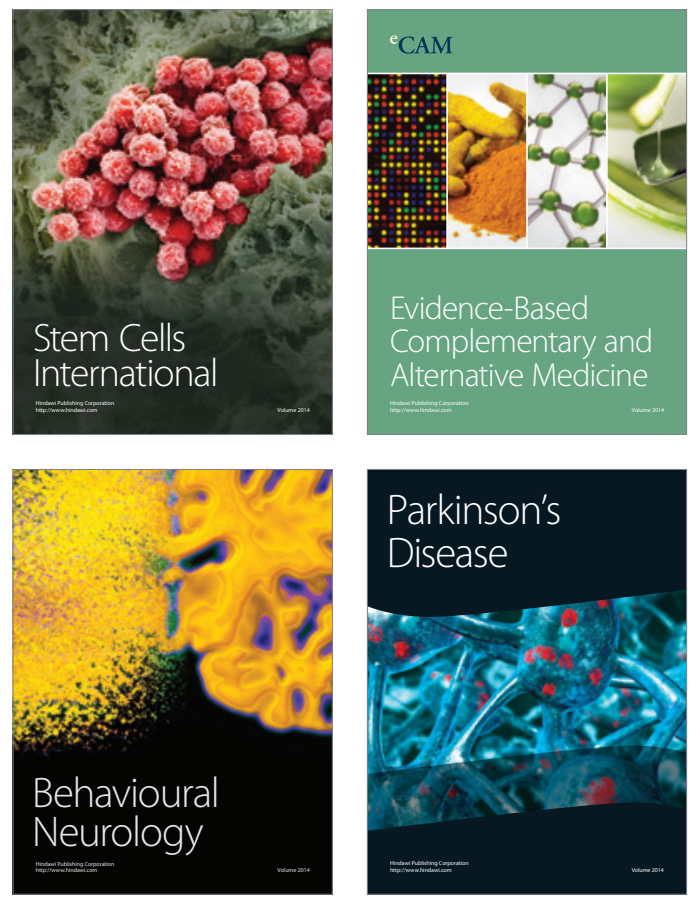
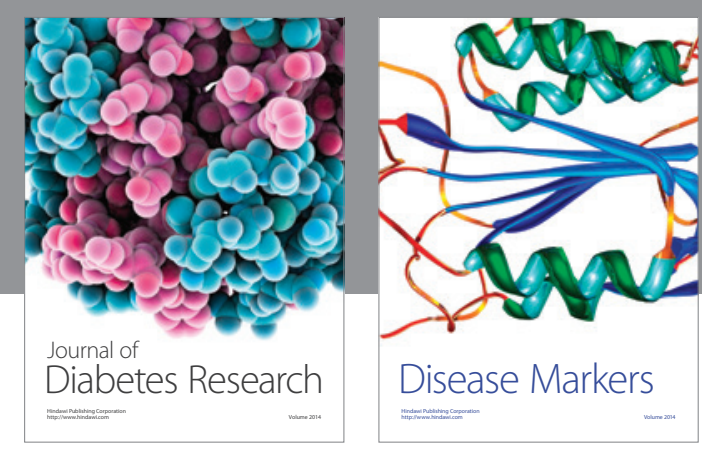

Disease Markers
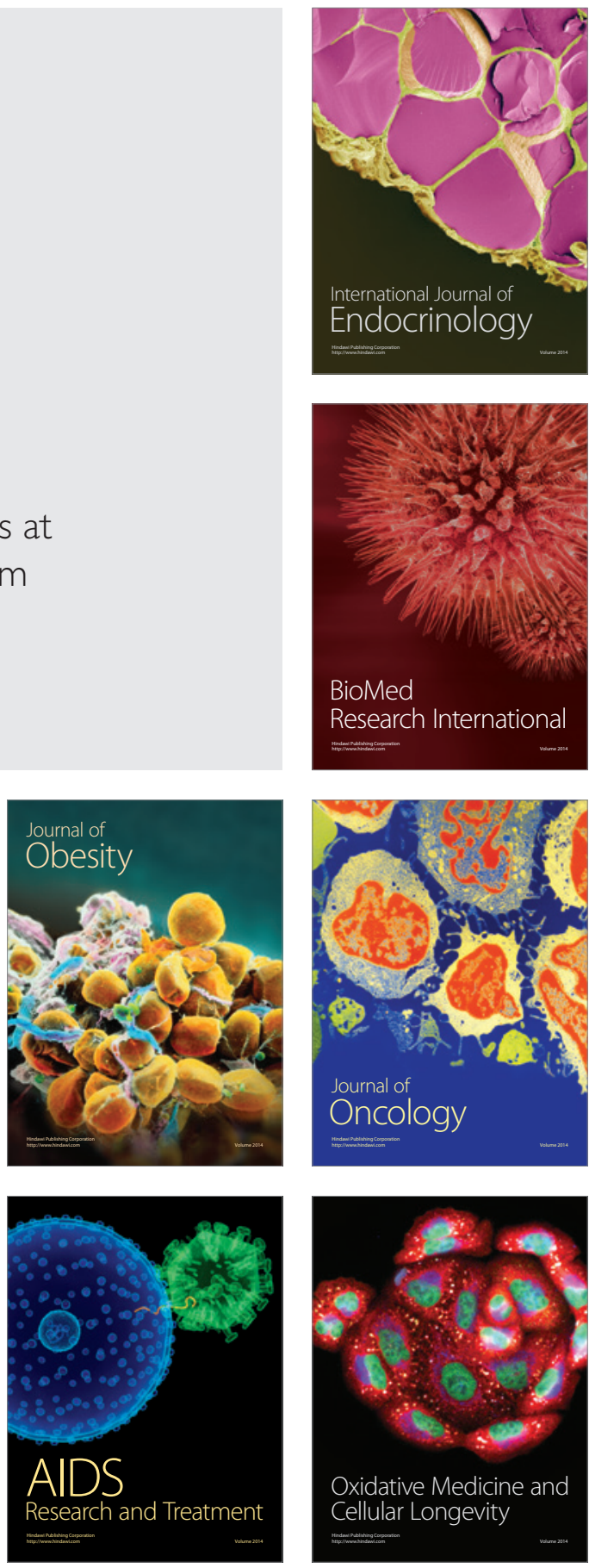